\title{
Ocular adnexal marginal zone B cell lymphoma infiltrated by lgG4-positive plasma cells
}

\author{
Toshinobu Kubota, ${ }^{1}$ Suzuko Moritani, ${ }^{2}$ Tadashi Yoshino, ${ }^{3}$ Hirokazu Nagai, ${ }^{4}$ \\ Hiroko Terasaki ${ }^{5}$
}

${ }^{1}$ Department of Ophthalmology, National Hospital Organization, Nagoya Medical Center, Nagoya, Japan 2Department of Pathology, National Hospital Organization, Nagoya Medical Center,

Nagoya, Japan

${ }^{3}$ Department of Pathology, Okayama University Graduate School of Medical, Dentistry and Pharmaceutical Science, Okayama, Japan ${ }^{4}$ Department of Internal Medicine, National Hospital Organization, Nagoya Medical Center, Nagoya, Japan ${ }^{5}$ Department of Ophthalmology, Nagoya University Graduate School of Medicine, Nagoya Japan

\section{Correspondence to}

Toshinobu Kubota, Department of Ophthalmology, National Hospital Organization, Nagoya Medical Center, 4-1-1, Sannomaru, Naka-ku, Nagoya-shi, Aichi-ken, 460-0001, Japan; ganiky@nnh.hosp.go.jp

Accepted 26 August 2010 Published Online First 27 October 2010

\section{ABSTRACT}

Aims To report the clinicopathological characteristics of patients with ocular adnexal marginal zone B cell lymphoma (MZBL) with IgG4-positive plasma cells. Methods 114 biopsy samples of ocular adnexal MZBLs were analysed. MZBLs with IgG4-positive plasma cells were included when the $\lg G 4: \lg G$ ratio was $>40 \%$ (IgG4-related group). The serum levels of each subclass of immunoglobulins and soluble interleukin-2 receptor in the IgG4-related group were compared with those in 61 consecutive patients having MZBL without IgG4-positive plasma cells (IgG4-unrelated group). They were also compared with those in 10 patients having ocular adnexal IgG4-related lymphoplasmacytic disorder (lgG4-related inflammatory group).

Results Ten (9\%) of the patients were diagnosed with MZBL with IgG4-positive plasma cells. The IgG4-related group had a significantly greater degree of sclerosis and reactive follicles in the MZBLs ( $p=0.0004$ and $p=0.01$, respectively). The serum levels of $\lg G, \lg G 1, \lg G 4, \lg E$ and soluble interleukin 2 receptor in the IgG4-related group were significantly higher than those in the IgG4-unrelated group ( $p=0.003, p=0.009, p<0.0001$, $p<0.0001$ and $p=0.0007$, respectively). The serum levels did not differ significantly from those of the IgG4-related inflammatory group. The IgG4-related group also had reactive IgG4-positive lymphoplasmacytic infiltrations in the recurrent lesion and in the stomach. Conclusions IgG4-positive plasma cells had infiltrated into ocular adnexal MZBLs in $9 \%$ of cases. It is suggested that ocular adnexal MZBLs with IgG4-positive plasma cells have unique histological and serological characteristics that overlap those of ocular adnexal IgG4-related lymphoplasmacytic infiltrative disorder and systemic conditions.

\section{INTRODUCTION}

Ocular adnexal marginal zone B cell lymphomas (MZBLs) make up the majority of lymphomas arising from the ocular adnexa. They are characterised histologically by the presence of reactive follicles in up to $64 \%$ of cases, sclerosis in up to $20 \%$ of cases, and plasma cells in up to $35 \%$ of cases. ${ }^{1}$ Among the inflammatory disorders arising from the ocular adnexa, the IgG4-related lymphoplasmacytic infiltrative disorder is characterised histologically by infiltration by IgG4-positive plasma cells with reactive lymphoid hyperplasia and sclerosing inflammation. ${ }^{2}$ Ocular adnexal MZBLs are reported to arise in IgG4-related sclerosing dacryoadenitis, indicating a possible link between the two conditions. ${ }^{3}$ However, clinical information about ocular adnexal MZBLs with IgG4-positive plasma cells is not available. In addition, any causal relationship between ocular adnexal MZBLs with IgG4-positive plasma cells and IgG4-related lymphoplasmacytic infiltrative disorder has not been established.

Thus, the purpose of this study was to determine the clinicopathological characteristics of ocular adnexal MZBLs infiltrated by IgG4-positive plasma cells. To accomplish this goal, we analysed patients with ocular adnexal MZBL with IgG4-positive plasma cells and compared the findings with those in patients with ocular adnexal MZBLs without IgG4-positive plasma cells and patients with ocular adnexal IgG4-related lymphoplasmacytic infiltrative disorder.

\section{PATIENTS AND METHODS \\ Patients}

The procedures used in this study conformed to the tenets of the Declaration of Helsinki and were approved by the Ethics Committee at Nagoya Medical Center, Nagoya, Japan. All patients provided signed informed consent after the procedures and possible outcomes were explained.

Patients with secondary ocular adnexal lymphomas were excluded from this study. The medical records of 114 patients with primary ocular adnexal MZBL who were examined between April 2001 and December 2009 were evaluated. A complete medical history and laboratory data that included the levels of each immunoglobulin and soluble interleukin 2 receptor (sIL-2R) were recorded. The criterion used to diagnose ocular adnexal MZBL with IgG4-positive plasma cells was an IgG4:IgG ratio $>40 \%$. Of the 114 patients, 10 had ocular adnexal MZBLs with IgG4-positive plasma cells (IgG4-related group).

\section{Clinical data}

We recorded the age, gender, laterality, lesion location, systemic evaluations, treatments, response to therapy and clinical follow-up findings of the 10 patients in the IgG4-related group. The pretreatment stage was determined by whole-body CT scans of the neck, chest, abdomen and pelvis. In addition, bone marrow biopsy and gastroscopy were performed. The disease stage at the time of the diagnosis was classified according to that modified for extranodal diseases ${ }^{4}$ and the American Joint Committee on Cancer classification. ${ }^{5}$

\section{Histopathology, immunohistochemistry and molecular genetic analysis}

Biopsy specimens from the ocular adnexal lesions were collected from all patients. Part of the biopsy 
specimen was embedded in paraffin for conventional histological and immunohistochemical analyses, and the remainder was immediately frozen and used for Southern blot analysis. All biopsy specimens were examined for morphological features, and classified according to the WHO classification. ${ }^{6}$ The immunophenotype, based mainly on CD20-positive, CD5negative, CD10-negative, CD23-negative and cyclin D1-negative expression (Dako, Glostrup, Denmark), and $\kappa$ and $\lambda$ (by in situ hybridisation; Ventana Medical Systems, Oro Valley, Arizona, USA) was also determined. The IgG-positive and IgG4-positive plasma cells were detected by immunostaining for IgG (polyclonal; Dako) and IgG4 (MC011; The Binding Site Group, Birmingham, England). To determine the number of IgG4-positive or IgG-positive cells, the areas with the highest density of IgG4-positive cells were evaluated. In each specimen, the mean number of IgG4-positive plasma cells was determined from three high-power fields by using methods previously described. ${ }^{3}$ One high-power field covered an area of $0.196 \mathrm{~mm}^{2}$ (magnification $\times 400$; Nikon microscope, Tokyo, Japan). Patients with an IgG4: IgG plasma cell ratio $>40 \%$ in a high-power field were placed in the group with ocular adnexal MZBLs with IgG4-positive plasma cells.

Southern blot analysis was performed on the specimens to detect $B$ cell clonality, that is, to determine if immunoglobulin heavy chain gene rearrangements had occurred. A PCR method was performed from the formalin-fixed and paraffin-embedded specimens by methods previously described ${ }^{7}$ to detect B cell clonality when fresh frozen biopsy samples were not available.

\section{Laboratory data}

Laboratory data were determined from peripheral blood collected from all patients. The serum levels of IgA, IgM, total $\mathrm{IgG}$, IgE and sIL-2R were analysed at the time of diagnosis and the follow-up examinations. Subclasses of IgG (IgG1, 2, 3 and 4) were collected from April 2007 to December 2009. Each subclass of IgG was analysed retrospectively.

\section{Treatments}

Table 1 shows the treatments for each patient. For the initial treatment, all patients except for patients 5 and 6 received radiotherapy at a dose of $30 \mathrm{~Gy}$. Following radiotherapy, all patients were carefully monitored, and cyclophosphamide/ doxorubicin/vincristine/prednisone (CHOP) and/or rituximab, along with the regimen used to treat low-grade non-Hodgkin lymphoma, were administered. This approach was based on the criteria of either rapid enlargement of the systemic tumour or appearance of clinical signs and symptoms, including B symptoms.

\section{Statistical analyses}

We compared the incidence of sclerosing and follicular lesions in the IgG4-related and IgG4-unrelated groups using the $\chi^{2}$ or Fisher's exact tests. The laboratory results were compared between the IgG4-related group and 61 consecutive patients in the IgG4-unrelated group, as were those between the IgG4related group and 10 patients with ocular adnexal IgG4-related lymphoplasmacytic disorder (IgG4-related inflammatory group), all using the Mann-Whitney test. All statistical analyses were performed on a personal computer with the SPSS statistical package for Windows (Version 12.0; SPSS, Chicago, Illinois, USA). A $p$ value $<0.05$ was considered to be statistically significant.

\section{RESULTS}

\section{Clinical data}

Among the 114 patients with ocular adnexal MZBLs, 10 (9\%) met the criterion based on the immunostaining for IgG4 and IgG. Table 1 shows the distribution of the age, gender, laterality, American Joint Committee on Cancer staging, Ann Arbor clinical staging, initial and second treatments and outcomes for the IgG4-related group. The findings for the two patients with polyclonal hypergammaglobulinaemia have been reported previously. 8

\section{Histopathology, immunohistochemistry and molecular genetic analysis}

All 114 biopsy specimens of the ocular adnexa were diagnosed as MZBLs based on histopathological and immunohistochemical results. The histological study of ocular adnexal MZBLs showed sclerosing changes in $48 \%(55 / 114)$ of the cases and reactive follicles in 39\% (44/114).

In the IgG4-related group (figures 1 and 2), the histological study showed sclerosing lesions in all $(10 / 10)$ and reactive follicles in $80 \%$ (8/10). The IgG4:IgG ratio for biopsy samples of the IgG4-related group ranged from 1.0 to 0.43 , in contrast to that of the IgG4-unrelated group (figure 3), which ranged from 0.2 to 0 . All biopsy specimens showed light-chain restrictions by in situ hybridisation and also showed immunoglobulin heavychain gene rearrangement by Southern blot analysis (data not available for patients 1 and 2).

The ocular adnexal recurrent lesion for patient 2 showed lymphoplasmacytic proliferation with IgG4-positive plasma

Table 1 Clinical characteristics of 10 patients with marginal zone B cell lymphoma with IgG4-positive plasma cells

\begin{tabular}{|c|c|c|c|c|c|c|c|}
\hline $\begin{array}{l}\text { Patient } \\
\text { no. }\end{array}$ & $\begin{array}{l}\text { Age (years)/ } \\
\text { gender }\end{array}$ & Laterality & Clinical stage* & $\begin{array}{l}\text { Initial } \\
\text { treatment }\end{array}$ & Events during follow-up & Second treatment & $\begin{array}{l}\text { Outcome and follow-up } \\
\text { (months) }\end{array}$ \\
\hline 1 & $66 / M$ & Bilateral & T2cN4M0/III & Radiation & $\begin{array}{l}\text { Malignant transformation to } \\
\text { diffuse large cell type }\end{array}$ & $\mathrm{CHOP}$ and rituximab & Died from disease (36) \\
\hline 3 & $67 / F$ & Left & T2cNOMO/IE & Radiation & $\begin{array}{l}\text { Gastric carcinoma and LPI, } \\
\text { developing TNM staging N4 }\end{array}$ & $\begin{array}{l}\text { Gastrectomy, } \mathrm{CHOP} \\
\text { and rituximab }\end{array}$ & AOD (70) \\
\hline 4 & 75/M & Left & T2cNOMO/IE & Radiation & Developing TNM staging N4 & ND & Died from other cause (65) \\
\hline 7 & $61 / \mathrm{M}$ & Left & T2cNOMO/IE & Radiation & Developing TNM staging N4 & ND & AWD (73) \\
\hline 8 & 90/M & Left & T2cN4M0/III & Radiation & None & ND & $\mathrm{AOD}(9)$ \\
\hline 9 & $65 / \mathrm{M}$ & Right & T2bNOMO/IE & Radiation & None & ND & AOD (26) \\
\hline 10 & $64 / \mathrm{M}$ & Right & T2cNOMO/IE & Radiation & None & ND & AOD (26) \\
\hline
\end{tabular}

${ }^{*}$ American Joint Committee on Cancer staging and Ann Arbor staging.

AOD, alive without disease; AWD, alive with disease; CHOP, cyclophosphamide, doxorubicin, vincristine, prednisone; LPI, lymphoplasmacytic infiltrations; TNM, tumour, node, metastases. 

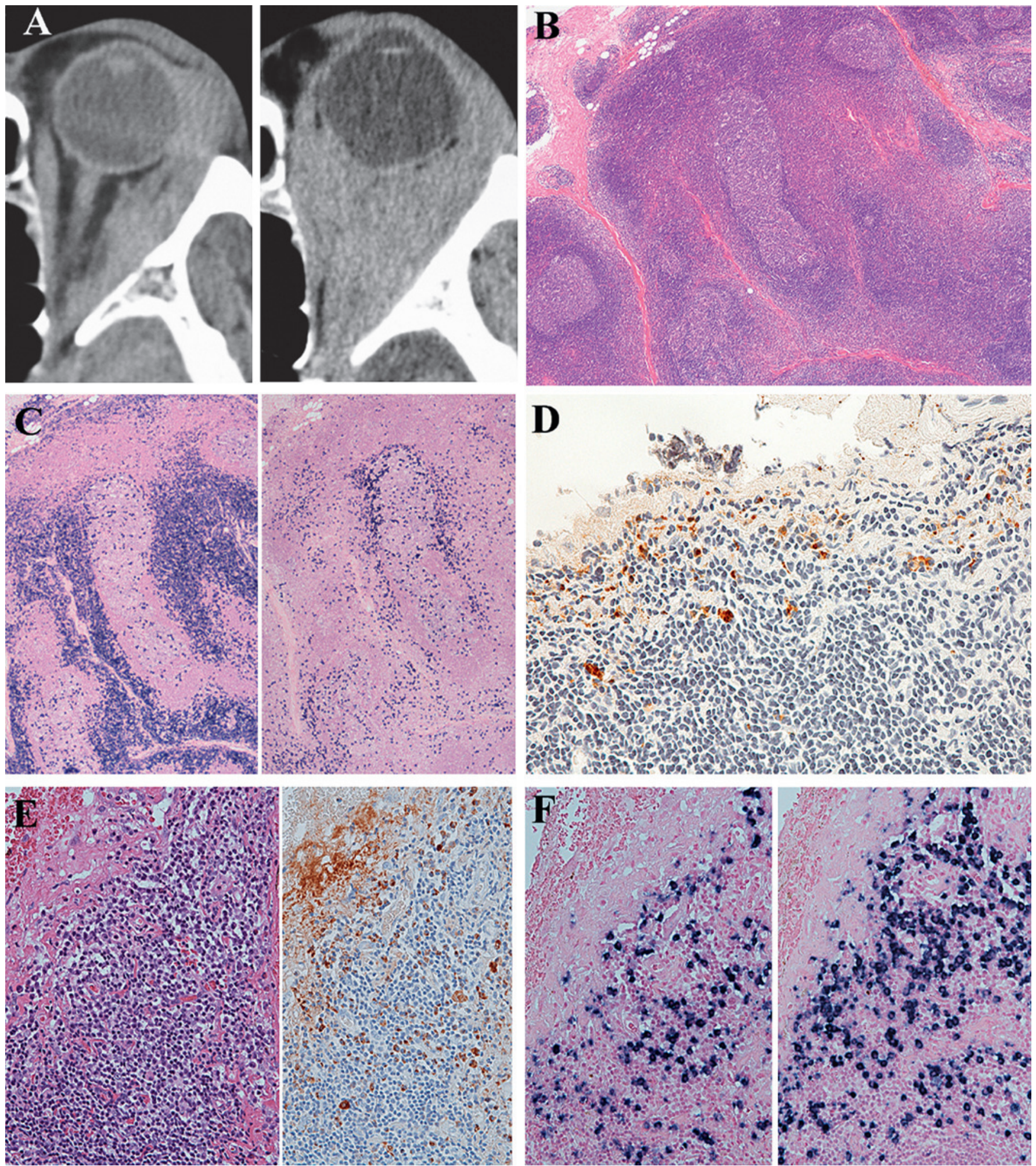

Figure 1 Initial and second biopsy specimens for recurrent lesions of patient 2. (A) CT images showing the tumour located in the left posterior orbit (left) at the time of diagnosis and recurring diffusely in the left posterior orbit (right) 53 months after radiotherapy. (B) Initial biopsy specimen showing proliferation of lymphoid cells with abundant follicles and sclerosis. H\&E staining, original magnification $\times 40$. (C) Immunostaining for $\lambda$ (left) and $\kappa$ (right) of the initial biopsy specimen shows light-chain restriction. In situ hybridisation, original magnification $\times 40$. (D) Immunostaining for IgG4 shows IgG4-positive plasma cells. The IgG4:IgG ratio was 0.43 . Immunoperoxidase staining, original magnification $\times 400$. (E) Second biopsy samples for recurrent lesions showing reactive lymphoplasmacytic proliferations. H\&E staining, original magnification $\times 200$. Immunostaining for IgG4 shows IgG4-positive plasma cells in the recurrent lesions. Right, the $\operatorname{lgG} 4: \lg G$ ratio was 0.62 . Immunoperoxidase staining, original magnification $\times 200$. (F) Immunostaining for $\lambda$ (left) and $\kappa$ (right) does not show light-chain restrictions. In situ hybridisation, original magnification $\times 200$. Southern blot analysis did not detect heavy-chain gene rearrangement. 
Figure 2 Histological and immunohistochemical findings in conjunctival marginal zone $B$ cell lymphoma with IgG4-positive plasma cells from patient 6 . (A) Salmon-pink mass lesions on the left bulbar conjunctiva. CT image shows medial rectus muscle enlargement (insert). (B) Histological study shows dense lymphocytic proliferation with sclerosis and follicles. H\&E staining, original magnification $\times 40$. (C) Immunostaining for $\lambda$ (left) and $\kappa$ (right) shows lightchain restriction. Southern blot analysis shows immunoglobulin heavy-chain gene rearrangement. In situ hybridisation, original magnification $\times 40$. (D) Higher magnification shows small and medium-sized lymphocytes with plasma cells and sclerosis. H\&E staining, original magnification $\times 400$. (E) Another higher magnification shows lymphoplasmacytic infiltrations with abundant sclerosing lesions. H\&E staining, original magnification $\times 400$. (F) Immunostaining for IgG4 reveals IgG4-positive plasma cells in the lymphoplasmacytic lesions. The lgG4: IgG ratio was 0.53 . Immunoperoxidase staining, original magnification $\times 400$.
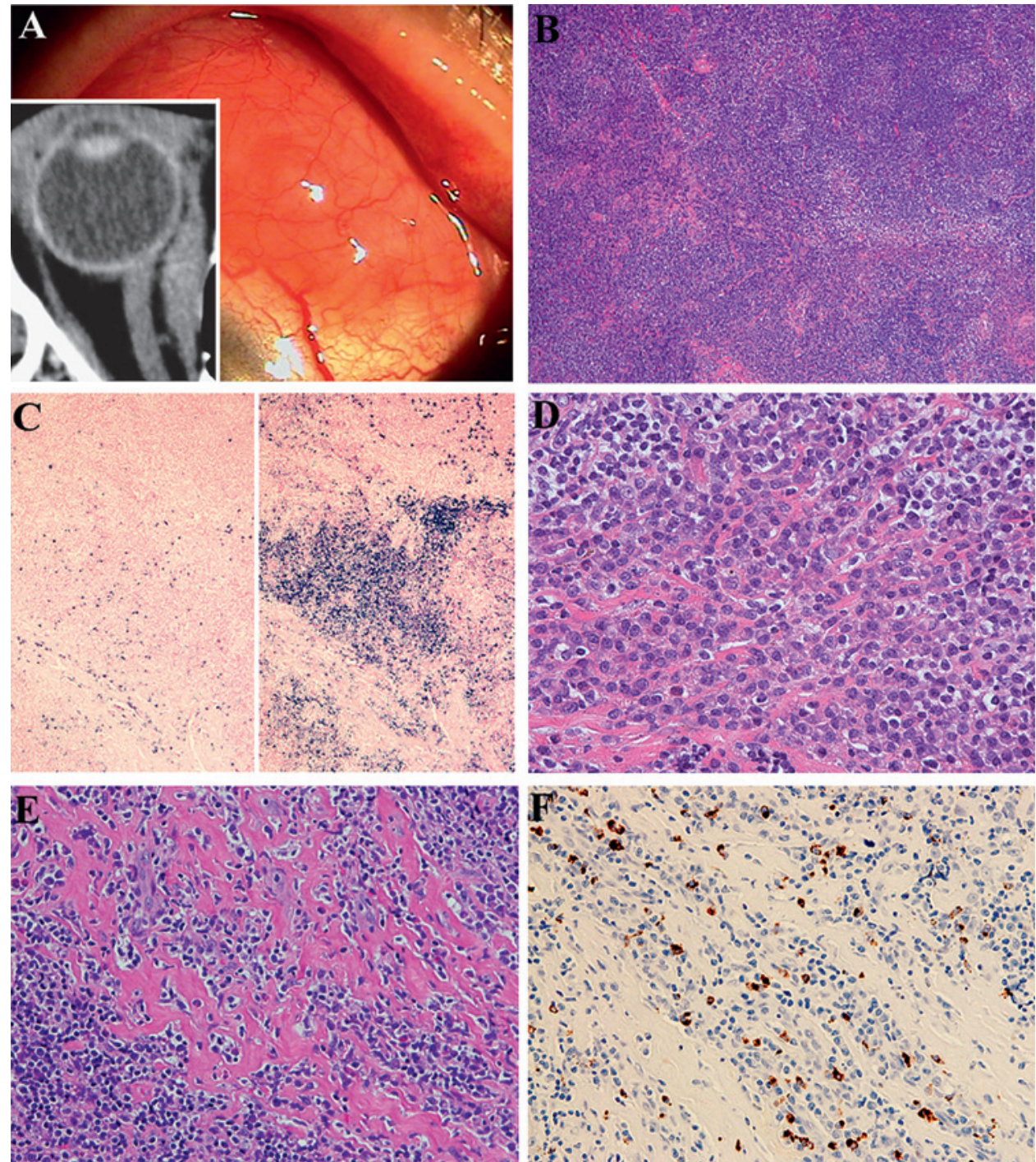

Figure 3 Findings in a 67-year-old man with bilateral conjunctival marginal zone B cell lymphoma without IgG4-positive plasma cells. (A) Salmon-pink mass lesions proliferate on the left bulbar conjunctiva. (B) Histology (left) of the lesion shows lymphoid cells proliferating without sclerosis and follicles. H\&E staining, original magnification $\times 100$. The specimen showed light-chain restriction by in situ hybridisation and immunoglobulin heavychain gene rearrangement by Southern blot analysis. Immunostaining for lgG4 (right) does not show IgG4-positive plasma cells. Immunoperoxidase staining, original magnification $\times 100$. 

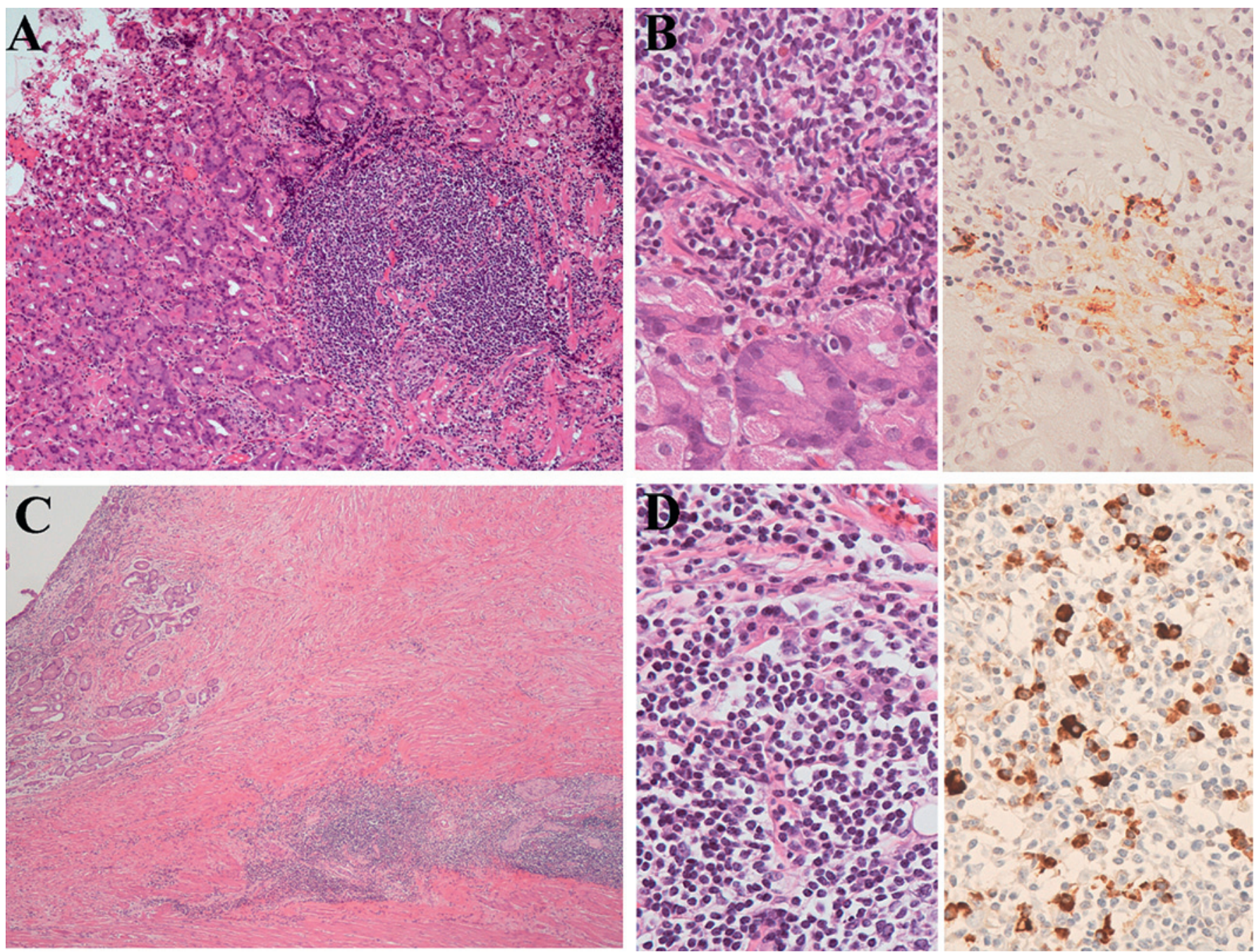

Figure 4 Gastric biopsy samples of patients 2 and 3. (A) Histology of patient 2 shows lymphoplasmacytic proliferations in the stomach. H\&E staining, original magnification $\times 100$. Immunostaining did not show light-chain restriction; however, the analysis of the specimen on PCR showed immunoglobulin heavy-chain gene rearrangement. (B) Higher magnification (left) shows lymphoplasmacytic infiltrations. H\&E staining, original magnification $\times 400$. Immunostaining for IgG4 (right) shows IgG4-positive plasma cells. The IgG4:IgG ratio was 0.67. Immunoperoxidase staining, original magnification $\times 400$. (C) Histology of patient 3 shows lymphoplasmacytic proliferations. H\&E staining, original magnification $\times 100$. Immunostaining did not show light-chain restriction; however, the analysis of the specimen on PCR showed immunoglobulin heavy-chain gene rearrangement. (D) Higher magnification (left) shows lymphoplasmacytic infiltrations. H\&E staining, original magnification $\times 400$. Immunostaining for IgG4 (right) showed IgG4-positive plasma cells. The $\lg G 4$ :IgG ratio was 0.70 . Immunoperoxidase staining, original magnification $\times 400$.

cells and did not show either light-chain restriction or immunoglobulin heavy-chain gene rearrangement (figure 1). Gastric biopsy samples during follow-up periods from patients 2 and 3 showed reactive lymphoid proliferation with IgG4-positive plasma cells (figure 4). Immunostaining did not show light-chain restriction by in situ hybridisation. PCR showed immunoglobulin heavy-chain gene rearrangement from the gastric sample of patients 2 and 3 .

Statistical analyses showed that biopsy samples from the IgG4-related group were significantly associated with sclerosing infiltrations ( $100 \%$ vs $43 \% ; p=0.0004$; Fisher's exact test), reactive follicles ( $80 \%$ vs $35 \%$; $=0.01$; Fisher's exact test) compared with those from the IgG4-unrelated group.

\section{Systemic evaluations}

Three patients (30\%) had systemic lymphadenopathy at the time of diagnosis (figure 5) involving the chest (patients 6 and 8), axillae (patient 6), and abdomen (patient 1). In contrast, among the IgG4-unrelated group, seven (7\%) had systemic lymphadenopathy at the time of diagnosis. The IgG4-related group had significant systemic lymphadenopathy at the time of diagnosis compared with that of the IgG4-unrelated group (30\% vs $7 \%$; $p=0.04$; Fisher's exact test). Patients 3, 4, 5 and 7 had stage I disease but later developed systemic lymphadenopathy that involved the chest (patients 3, 4 and 7), the axillae (patients 3 and 5), abdomen (patients 3 and 4) and pelvis (patient 4).

\section{Treatment and outcome}

Table 1 shows the results of the systemic evaluations, treatment and outcome. Following radiotherapy, all patients achieved complete regression in the irradiated field. Patients 2 and 3 relapsed in the irradiation field after 65 and 24 months, respectively, and also had IgG4-positive lymphoplasmacytic proliferations in the stomach. Patient 3 additionally developed gastric carcinoma. Patient 2 received rituximab treatment, and the recurrent lesion regressed but then gradually relapsed again. Patient 3 received gastrectomy and rituximab and CHOP therapy, and had no evidence of the disease at the final examination. 

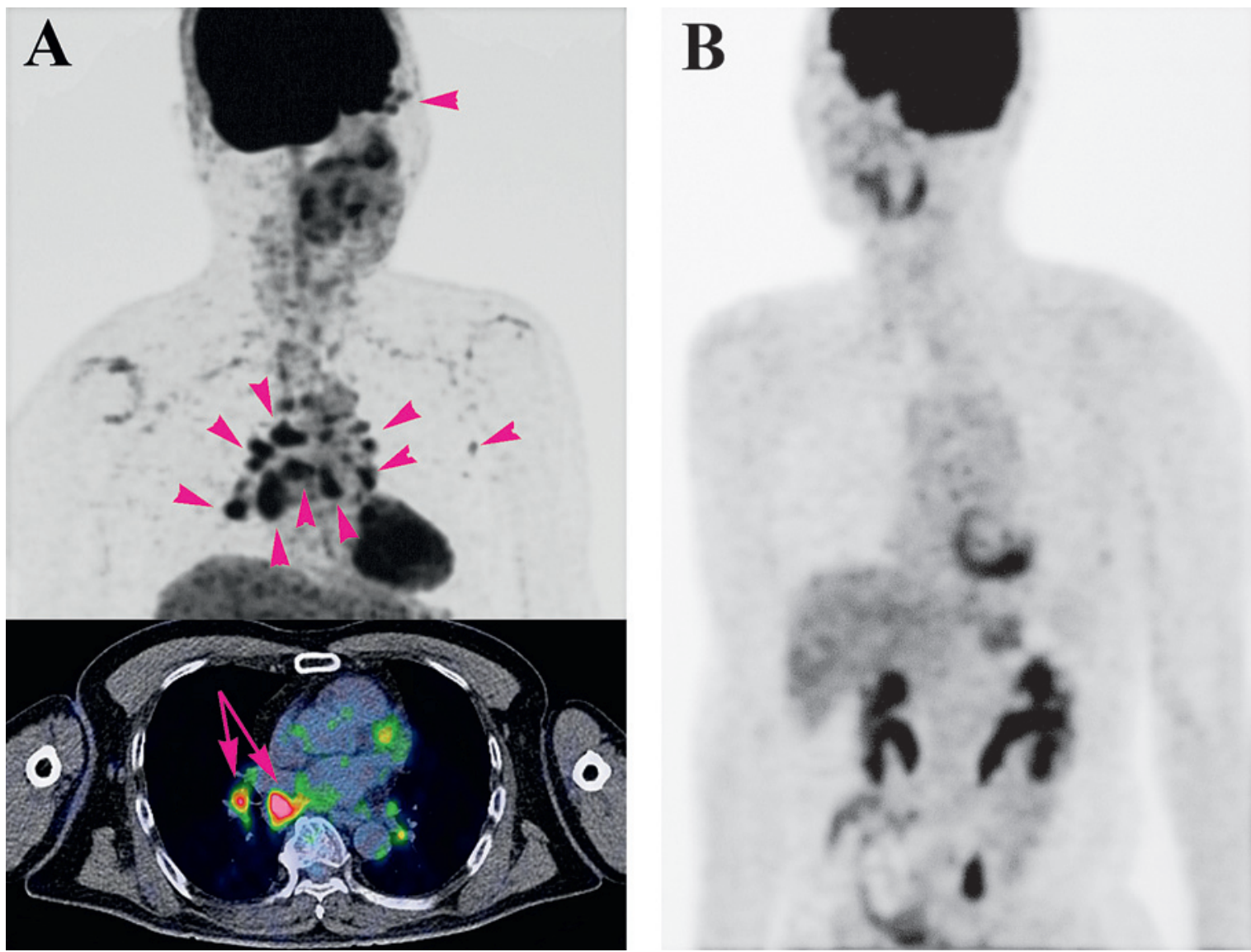

Figure 5 Fluorodeoxyglucose F-18 (FDG) positron emission tomography at the initial examination of patient 6 (A) whose ocular data are presented in figure 3 (B). FDG positron emission tomography of patient 6 showed accumulation of FDG in the right ocular adnexa, chest and left axillae (arrowheads) at the time of the diagnosis. Fusion images demonstrate not only swelling of several bronchomediastinal lymph nodes (arrows), but also the metabolic activity of the lesions. In contrast, the patient in figure 3 shows none of the accumulations including in the ocular adnexa.

\section{Laboratory data}

Table 2 presents the mean serum levels of $\operatorname{IgA}$, IgM, IgG1-4, IgE and sIL-2R receptor for the 10 patients in the IgG4-related group, the 61consecutive patients in the IgG4-unrelated group, and the 10 patients in the IgG4-related inflammatory group. The serum levels of IgG, IgG1, IgG4, IgE and sIL-2R receptor in the IgG4-related group were significantly higher than those in the IgG4-unrelated group (table 2; $p=0.003, p=0.009$, $p<0.0001, \quad p<0.0001$ and $p=0.0007$, respectively; Mann-Whitney test). In contrast, the serum levels of IgM were significantly lower than those in the IgG4-unrelated group $(p=0.02$; Mann-Whitney test), although, for the two groups, serum levels of IgM were within normal limits. Between the IgG4-related group and the IgG4-related inflammatory group, neither immunoglobulin nor sIL-2R levels differed significantly.

Table 2 Serological data of patients with ocular adnexal MZBL with or without IgG4-positive plasma cells, and patients with ocular adnexal lgG4-related lymphoplasmacytic disorder

\begin{tabular}{|c|c|c|c|c|c|}
\hline Serological data (normal range) & $\begin{array}{l}\text { IgG4-related } \\
\text { group, } n=10\end{array}$ & $\begin{array}{l}\text { IgG4-unrelated } \\
\text { group, } \mathrm{n}=61\end{array}$ & $\begin{array}{l}\text { IgG4-related inflammatory } \\
\text { group, } \mathrm{n}=10\end{array}$ & p Value* & p Value $\dagger$ \\
\hline $\lg A(110-410 \mathrm{mg} / \mathrm{dl})$ & $214(109)$ & $228(103)$ & $229(149)$ & 0.6 & 0.7 \\
\hline $\operatorname{lgM}(33-190 \mathrm{mg} / \mathrm{dl})$ & $102(58)$ & $157(93)$ & $78(58)$ & 0.02 & 0.09 \\
\hline Total IgG $(870-1700 \mathrm{mg} / \mathrm{dl})$ & 2432 (1944) & $1287(406)$ & 2732 (1749) & 0.003 & 1.0 \\
\hline $\operatorname{lgG1}(320-748 \mathrm{mg} / \mathrm{dl})$ & $858(193)$ & $655(190)$ & $1047(418)$ & 0.009 & 0.4 \\
\hline $\operatorname{lgG} 2(208-754 \mathrm{mg} / \mathrm{dl})$ & $607(232)$ & $494(172)$ & $836(465)$ & 0.2 & 0.4 \\
\hline $\operatorname{lgG} 3(7-88 \mathrm{mg} / \mathrm{dl})$ & $86(72)$ & $44(35)$ & $66(47)$ & 0.2 & 0.9 \\
\hline $\operatorname{lgG} 4(5-105 \mathrm{mg} / \mathrm{dl})$ & $415(295)$ & $48(46)$ & 901 (890) & $<0.0001$ & 0.2 \\
\hline $\lg \mathrm{E}(<170 \mathrm{IU} / \mathrm{ml})$ & $1581(1717)$ & $293(509)$ & $1020(1159)$ & $<0.0001$ & 0.2 \\
\hline slL-2R (135-483 U/ml) & $943(525)$ & 465 (392) & 941 (579) & 0.0007 & 0.9 \\
\hline
\end{tabular}

Values are mean (standard deviation)

IgG4-related group: patients having ocular adnexal MZBL with IgG4-positive plasma cells; IgG4-related inflammatory group: patients with ocular adnexal IgG4-related lymphoplasmacytic infiltrative disorder; IgG4-unrelated group: patients having ocular adnexal MZBL without IgG4-positive plasma cells.

*IgG4-related group versus IgG4-unrelated group.

†IgG4-related group versus IgG4-related inflammatory group.

MZBL, marginal zone B cell lymphoma; slL-2R, soluble interleukin-2 receptor. 


\section{DISCUSSION}

Nine per cent of the cases of ocular adnexal MZBLs consisted of IgG4-positive plasma cells with sclerosing and reactive follicular lesions. Sclerosing and reactive follicles had a relatively high incidence in our cases of ocular adnexal MZBLs. However, on the basis of the unique systemic and serological characteristics of the IgG4-related group, we suggest that IgG4-positive plasma cells with sclerosing and reactive follicles are specific inflammatory lesions in ocular adnexal MZBLs.

IgG4-positive plasma cell infiltrations with sclerosing and reactive follicles in the IgG4-related group were similar to those already published for the IgG4-related inflammatory group, ${ }^{2}$ although they are distinct different clinical entities. Interestingly, gastric biopsy samples in the IgG4-related group revealed IgG4-positive lymphoplasmacytic infiltrations. A close association of histology and serum abnormalities between the IgG4related group and the IgG4-related inflammatory group suggests that the pathogenesis of IgG4-positive plasma cell infiltrations into ocular adnexal MZBLs may be induced by conditions similar to both. Thus, pathogenesis of IgG4-positive plasma cell infiltrations into ocular adnexal MZBLs may be correlated with a systemic condition that induces unique serum abnormalities.

Ocular adnexal MZBLs with IgG4-positive plasma cells must be differentiated from ocular adnexal IgG4-related lymphoplasmacytic disorder. Our biopsy samples showed not only histological MZBLs but also B cell clonality. These analyses support the identification of our biopsy samples as MZBLs.

Ocular adnexal MZBLs with IgG4-positive plasma cells were typically associated with elevated levels of IgG4, IgE and sIL-2R, and polyclonal hypergammaglobulinaemia. One plausible hypothesis for these serological and immunological abnormalities may be that they are caused by in vivo activation of the immune system by activated Th2 cells. Activated Th2 cells produce $\operatorname{IgE}$ and induce polyclonal B cell activation, ${ }^{9}$ and IgG4 is induced by a modified Th2 response. ${ }^{10}$ Elevated levels of sIL-2R reflect the in vivo activation of the immune system. ${ }^{11}$ Thus, the cause of the serological abnormalities in the IgG4-related group may be correlated with activated Th2 cells.

Our study has several limitations. First, each subclass of IgG was collected retrospectively, and this may have led to some bias. Second, there were discrepancies in the B cell clonality between immunohistochemistry and PCR from a gastric sample of patients 2 and 3 . This may have been an incipient clone with a background of IgG4-positive lymphoplasmacytic infiltrations, although the result of the PCR could also be a false positive.

In conclusion, sclerosing and reactive follicular lesions with IgG4-positive plasma cells infiltrated into ocular adnexal MZBLs in $9 \%$ of cases. Patients having MZBL with IgG4-positive lymphoplasmacytic infiltrations characteristically had elevated serum levels of IgG4, IgE and sIL-2R, and systemic IgG4-positive plasma cell infiltrations, such as in the recurrent lesion and

\section{Take-home messages}

- Ocular adnexal marginal zone B cell lymphoma (MZBL) infiltrated by IgG4-positive plasma cells has significant sclerosis in the lesions.

- Patients with MZBL infiltrated by IgG4-positive plasma cells have unique serum abnormalities, that is, elevated levels of $\lg \mathrm{G} 4$, IgE and soluble interleukin-2 receptor, and polyclonal hypergammaglobulinaemia.

- Patients with MZBL infiltrated by IgG4-positive plasma cells also have reactive IgG4-positive lymphoplasmacytic infiltrations in the recurrent lesion and in the stomach.

stomach. We hypothesise that the pathogenesis of IgG4-positive plasma cell infiltrations into ocular adnexal MZBLs is correlated with a systemic condition that induces unique serum abnormalities.

Competing interests None.

Patient consent Obtained.

Ethics approval This study was approved by the Ethics Committee at Nagoya Medical Center, Nagoya, Japan.

Provenance and peer review Not commissioned; externally peer reviewed.

\section{REFERENCES}

1. Ferry JA, Fung CY, Zukerberg L, et al. Lymphoma of the ocular adnexa: a study of 353 cases. Am J Surg Pathol 2007;31:170-84.

2. Kubota T, Moritani S, Katayama M, et al. Ocular adnexal IgG4-related lymphoplasmacytic infiltrative disorder. Arch Ophthalmol 2010;128:577-84.

3. Cheuk W, Yuen HK, Chan AC, et al. Ocular adnexal lymphoma associated with IgG4 + chronic sclerosing dacryoadenitis: a previously undescribed complication of IgG4-related sclerosing disease. Am J Surg Pathol 2008;32:1159-67.

4. Carbone PP, Kaplan HS, Musshoff K, et al. Report of the Committee on Hodgkin's Disease Staging Classification. Cancer Res 1971;31:1860-1.

5. Coupland SE, White V, Rootman J, et al. TNM staging of ocular adnexal lymphomas. In: Edge SB, Fritz AG, Byrd DR, et al, eds. AJCC Cancer Staging Manual. 7th edn. New York, NY: Springer, 2009:583-9.

6. Swerdlow SH, Campo E, Harris NL, et al. WHO Classification of Tumours of Haematopoietic and Lymphoid Tissues, 4th edn. Lyon, France: International Agency for Research on Cancer, 2008.

7. van Dongen JJ, Langerak AW, Bruggemann $M$, et al. Design and standardization of PCR primers and protocols for detection of clonal immunoglobulin and T-cell receptor gene recombinations in suspect lymphoproliferations: report of the BIOMED-2 Concerted Action BMH4-CT98-3936. Leukemia 2003;17:2257-317.

8. Kubota T, Moritani S, Yoshino T, et al. Ocular adnexal mucosa-associated lymphoid tissue lymphoma with polyclonal hypergammaglobulinemia. Am J Ophthalmol 2008;145:1002-6.

9. Genton C, Wang Y, Izui S, et al. The Th2 lymphoproliferation developing in LatY136F mutant mice triggers polyclonal B cell activation and systemic autoimmunity. J Immunol 2006;177:2285-93.

10. Platts-Millis TA. Immediate hypersensitivity (Type I). In: Male D, Brostoff J, Roth DB, Roitt I, eds. Immunology. 7th edn. Philadelphia: Elsevier, 2006:423-48.

11. Rubin LA, Nelson DL. The soluble interleukin-2 receptor: biology, function, and clinical application. Ann Intern Med 1990;113:619-27. 